\title{
Collaborative Design Research: Linking universities with government policy-makers
}

\author{
DR HELEN NORRIE, University of Tasmania \\ JUDITH ABELL, University of Tasmania
}

\begin{abstract}
In an essay in The Endless City: The Urban Age Project (2007), Deyan Sudjic proposes that the problems of our cities can be understood and managed through collaboration between three groups: policymakers, builders and theorists. The Regional Urban Studies Laboratory (RUSL) led by the School of Architecture \& Design at the University of Tasmania provides collaborative practice-based research that links the academy - as theorists - with the local government - the policymakers and city builders. RUSL works directly with local authorities to examine urban issues in small towns and cities, developing collaborative processes that examine the specific nature of design issues that are socially, culturally and/or situationally conditioned. Research through the medium of design provides a process of iterative thinking, and the crossover between the disciplines of architecture, planning, sociology and economics provide fertile ground for research investigations. Relationships between the academy and political institutions further enrich this potential.
\end{abstract}

\section{KEYWORDS}

Urban, collaboration, design research, practice-led research, urban theory

\section{Introduction}

The development of cities is wrapped in a complex web of frequently conflicting social, economic and environmental concerns, and attaining a balance between these factors underpins contemporary urban settlements. In an essay in The Endless City: The Urban Age Project (2007), Deyan Sudjic proposes that the problems of our cities can be understood and managed through collaboration between three groups: policymakers, builders and theorists. The Regional Urban Studies Laboratory (RUSL - pronounced Russell) is a collaborative research project at the University of Tasmania's School of Architecture \& Design, which investigates urban issues in regional centres through practice-based research. Following Sudjic's model, RUSL is positioned as the theorist, examining the specific nature of urban design issues that are socially, culturally and/or situationally conditioned. Projects investigate 'real world' problems through collaborative research between the academy and local government (the policymakers and city builders). Research through the medium of design provides a process of iterative thinking, with the crossover between the disciplines of architecture, planning, sociology and economics providing fertile ground for research investigations. Relationships between the academy and political institutions further enrich this potential. 
Responding directly to the Australian context, RUSL establishes projects that explore urban issues for small cities and towns, investigating the design of urban space to create socially sustainable settlements. Projects employ diverse methods to explore design problems through speculation and testing of a range of spatial ideas against a set of criteria, questions or research issues. Projects are developed directly with local authorities, providing an opportunity to engage in a deep inquiry around fundamental urban issues, particularly those that are sited at the periphery of day-to-day operational concerns, but are central to broader scale strategic thinking. This collaborative practice-led research allows local authorities to examine issues for the future development of cities, and it also extends the university's research capacity through direct engagement with real-world issues. Projects are also developed collaboratively between academics and students, bridging the teaching-research nexus through the investigation of core urban issues that span across the disciplines of architecture, urban design, landscape architecture and planning. (Norrie 2014)

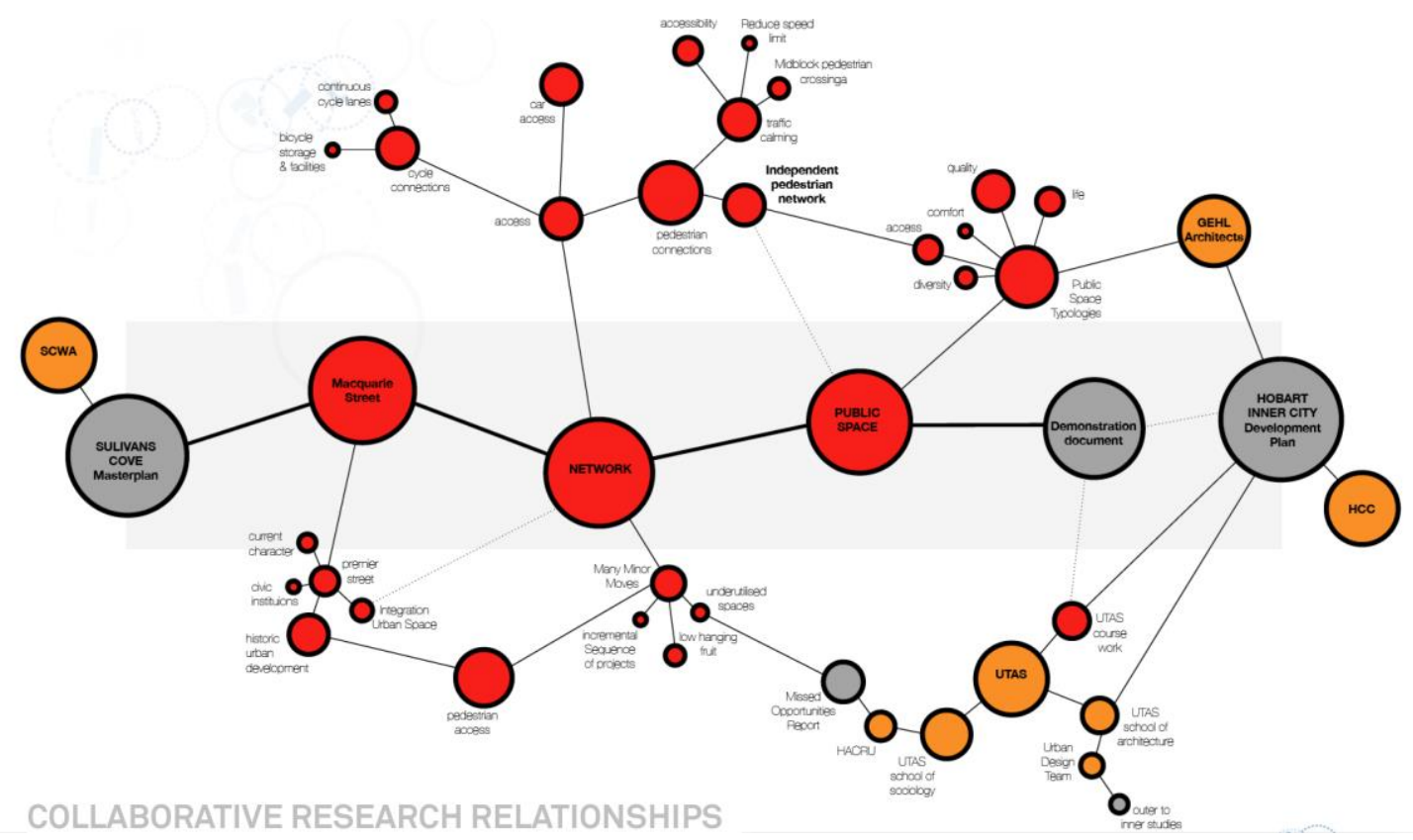

Figure 1: Mapping relationships of between organization and individuals engaging with key urban issue. Image: Alysia Bennett, 2009.

RUSL projects are developed as both academic research and as part of the Masters of Architecture (MArch) research unit, Advanced Design Research (ADR); a practiceled design research studio which develops speculative ideas for specific sites and urban precincts, with the aim of extending current understanding of specific problems. The research engages directly with contemporary theories on design research, drawing on the work of Christopher Frayling, Peter Downton, Jane Rendell, Donald. A. Schön, Murray Fraser and Shane Murray, to critically reflect on design research processes. The research engages in 'critical spatial practices', which draw on contemporary urban and landscape theory, to understand ways of creating more connected cities that foster social engagement. (Rendell 2013, 199) Research processes test the applicability of Frayling's tripartite description of design research in terms of research into/for/through design. (Frayling 1993) Critically reflecting on this research engages with a fourth mode of design research, which Downton describes as 
research about design, in which research processes are explicitly examined. (Downtown 2003) This paper provides an overview of RUSL projects and research processes, examining how this practice-led research integrates theory and practice, using emergent methodologies of research through design to explore ways of creating new knowledge that speculates on urban futures.

\section{What is Design Research?}

RUSL projects employ a process of practice-led design research that draws on diverse conceptual and theoretical approaches to develop propositional ideas, bridging the divide between theory and practice. Rather than providing answers to finite research questions, design research seeks to address particular problems and generate questions, through an open-ended process that is both projective and speculative. It involves multiple processes that utilise both established and emergent methodologies. Projects are characterized by the development of new knowledge, which is understood as the central definition of research by both the Australia Research Council's framework for assessing Excellence in Research Australia (ERA) and the Research Assessment Exercise (RAE) in Britain.

\section{Design Research Methods}

Peter Downton describes the process design of research as a kind of 'cheerful eclecticism,' rather than adhering to 'a dogma-driven set of methods developed and advanced by a particular school.' $(2003,11)$ He suggests that design is 'a way of inquiring, a way of producing knowledge,' that utilises a 'collection of methods, approaches, ideas and practices,' as well 'ideas from outside design, (which) need to be discussed to elucidate and elaborate ideas about design research.' $(2003,1,13)$ Downton notes that design research offers a 'looser view of method' than more traditional and formalised methodologies. $(2003,12)$ He highlights the deliberately indeterminate nature of designing, where often the outcome of a process or design investigation is entirely unknown, and both the structure and final output evolve throughout the life of the project. He observes that:

Design is not normally intended to produce a fully pre-conceived outcome, rather it is expected to produce change in the existing situation and hopefully offer fresh surprise and delight. $(2003,3)$

In defining design research, Jane Rendell draws on measures developed the Arts and Humanities Research Board (now the Arts and Humanities Research Council) in the UK in 1999 to assess funding for practice-led proposals, requiring the articulation of: research questions, methods, contexts and modes of dissemination. Rendell notes that within this definition there is no requirement for any kind of linear relationship between each element. She suggests that design research reverses the traditional order by generating questions rather than seeking to solve problems; both the research processes and final output evolve throughout the life of the project. Rendell also observes that this process may generate questions, rather than resolved outcomes. (2004, 143-144)

Christopher Frayling's article "Research in Art and Design," which was published in 1993, has become a touchstone in the discussion of design research. Frayling's 
differentiation of research into, for and through design is frequently used as a basis for discussing design research methods:

- Research into Design examines historical and theoretical perspectives, providing the advancement of new scholarship through alternative interpretations.

- Research for Design involves investigations conducted with a design application in mind, examining development and application of new materials, technologies and methods from other disciplines or sources.

- Research through Design takes design processes to constitute the research methodology itself, with the focus on bridging between product and process.

Rendell suggests that the understanding of research into and for have developed nonproblematically, partly because the work can be easily positioned within existing disciplinary modes in science and the humanities, whereas research through design is subject to debate around the relation between theory and practice. (2004, 143) Technical and materials-based research is assumed to follow the science model, and historical or theoretical investigation is taken to follow either a social sciences or humanities model, whereas design-based research employs hybrid processes from both of these models, and engages with more open-ended methods. $(2004,142)$.

Rendell observes that architecture encompasses several disciplines, bringing together different modes of research that are often kept separate; natural science, social science/humanities, history/theory and design/practice-led research. Rendell distinguishes between multidisciplinary research, which involves each discipline 'maintain(ing) their own distinct identities and ways of doing things,' and interdisciplinary processes in which 'individuals operate at the edge and in between disciplines and in doing so question the ways in which they usually work.' (2004, 145) She suggests that understanding different multi and inter-disciplinary processes allows for the "production of complex forms of research that are at once self-reflective and propositional.' (2004,146) This highlights the inherent open-ended and speculative nature of design research.

In considering how design research often borrows from more established research methodologies, Fraser suggests that while speculation and imagination are important to the scientist, the social scientist, or the historian, the creative aspect becomes the 'dominant part of the investigation' of design research, which introduces 'its own ideas of testing and evaluating, even in rather lateral or unexpected ways.' $(2013,2)$ Fraser notes that both design and research are 'projective undertakings equally rooted in uncertainty and contingency, and thus needing to oscillate between past, present and future conditions.' $(2013,4)$

Rendell describes research through design as a practice-led research, drawing on Schön's descriptions of 'reflection-in-action.' (Rendell 2013, 120) Central to this is the acceptance of non-linear research processes as the core of practice-led research, which may be conducted via iterative, generative or propositional processes, producing an outcome to then be reflected upon. (Rendell, 2004, 144) Schön observes that reflection-in-action creates an iterative, experimental process, involving the trial and error of testing: 
...we think critically about the thinking that got us into this fix or this opportunity; and we may, in the process, restructure strategies of action, understandings of phenomena, or ways of framing problems. ...Reflection gives rise to on-the spot experiment. We think up and try out new actions intended to explore the newly observed phenomena, test out our tentative understandings of them, or affirm the moves we have invented to change things for the better. (Schön 1987, 28)

However, Fraser contests that there are ways of understanding design research in architecture more broadly than the notion of reflection-in-action, and that

...we actually need a more dynamic and engaged model of design practice often signaled by the use of the term "praxis" as a condition which is far more critically engaged and socially proactive. (Fraser 2013,4)

Rendell suggests that the 'reflexive nature of a practice' helps define design as research, and highlights the 'critical spatial practices,' which incorporate the spatial, the temporal and the social; and are central to practice-led design research. (2013, 120)

Projects that put forward questions as the central tenet of the research, instead of, or as well as solving or resolving problems, tend to produce objects that critically rethink the parameters of the problem itself. (Rendell 2004,145)

These ideas can be understood through a discussion of RUSL projects, which utilise hybrid processes of research into, for and through design, examining issues that engage with spatial, temporal and social conditions of cities. (Rendell 2013, 120) Critical reflection on these projects creates another kind of design research, which can be understood as research about design, which 'enquires into what takes place when design is undertaken, and then seeks to find methods to improve or refine the observed activity.' (Murray 2013, 95) These projects provide case studies that demonstrate emergent methodologies, exploring the nexus between theory and practice, and providing differing modes of dissemination that communicate with the builders and policy-makers, while also addressing the demands of the structured target-driven outputs required by the university framework.

\section{RUSL as a case study}

At the broadest level, Regional Urban Studies Laboratory is concerned with the way we live in cities, particularly how cities are organized spatially, temporarily and socially, and how this is influenced by builders and policy-makers at a local, state and federal level. RUSL is primarily concerned with smaller scale cities and towns, places in which the critical mass of population presents specific issues regarding economies of scale. This presents a deliberate contrast with the current preoccupation with the needs of rapidly expanding major cities, both in Australia and worldwide. Research is motivated by the recognition that Australia has only five cities with more than one million people, and only eleven cities with a population of than 200,000, this means that beyond the major metropolitan centres Australia is a country of regional and remote communities. Although many towns and cities lack the critical mass of 
population to provide economic stability, these places also offer conditions of affordability and liveability that rival larger cities. (Figure 1)

RUSL develops practice-led research using case studies from towns and cities in the island state of Tasmania to speculate on urban futures. With a population of just over 500,000 people but with the geographic size of Ireland, Tasmania highlights a broader condition across regional Australia. Examining Tasmania as a case study for regional survival and revival shows specific problems faced by communities with critically small populations that are reliant on small and often singular economies. (Norrie, et.al. 2014) RUSL projects are outlined below, highlighting the scope of research questions, context, methods and dissemination, categories cited by Rendell above.

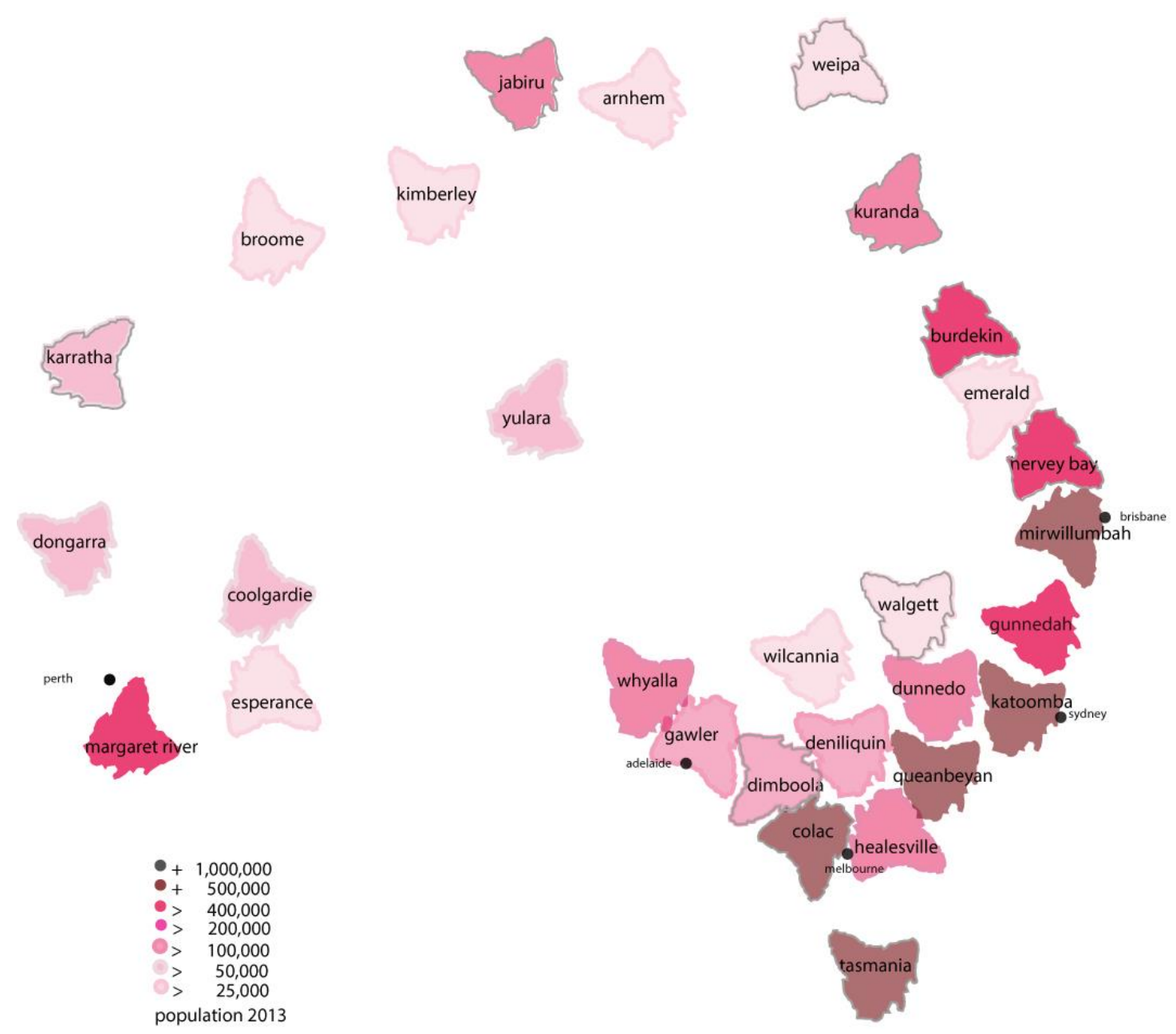

Figure 2: Mapping of population in regional areas of Australia with a similar geographic size to Tasmania. Image: Norrie, 2012.

\section{RUSL Research questions}

RUSL projects draw on an understanding between past, present and future, collating and communicating information about historic and current conditions as a way of building a dialogue that poses questions for urban futures. RUSL is founded on the belief that long-term strategic regional thinking, which examines the agency of different levels of government to address social, spatial and economic urban issues, is 
needed in order to develop future urban visions. RUSL is underpinned by the belief that a commitment to research, cooperation and coordination at a federal, state and local level is central to identifying sectors of opportunity that can provide development that supports the social and cultural life of settlements across regional Australia. (Norrie, et.al. 2014)

RUSL projects engage with a series of recurring themes, exploring different scales of thinking - regional, landscape/urban, local/social - thereby examining the broader question of civic engagement. Projects engage with spatial, temporal and social issues that are central to the design and development of the urban environment, from localised problems to broader-scale regional thinking. Although each project investigates a particular site-specific set of problems, it seeks to understand these in generic terms, so that findings can be applied in other locations. Common to all is an exploration of how settlements are shaped, addressing recurring questions, engaging with issues of movement and connectivity, and including an understanding of what is built where, by whom and how this supports a broader urban narrative:

- How to build a city or region around its landscape

- How to build a city or region around its culture- past, present and future

- How to support the social and cultural life of cities or regions

\section{RUSL Research context}

While current policy development in Australia focuses on the continual growth of major metropolitan centres, developing strategies to deal with issues that are the consequence of the size and scale of these cities, RUSL examines alternative issues at stake beyond metropolitan centres, highlighting the need for tailored strategies that ensure the future growth and resilience of smaller settlements.

RUSL projects draw on a range of contemporary theories on urban design and planning for the public realm. The work of Danish architect and urbanist, Jan Gehl, informs projects, particularly the ideas outlined in Cities for People (2010), which highlights the design of cities that prioritise social interaction and inclusive environments that improve the daily lives of individuals and communities. Gehl advocates for a process of life-space-building, which reverses the priorities of traditional processes of masterplanning that frequently overlook detailed issues at a human scale, particularly pedestrian movement and active social engagement. In considering how to develop cities around urban space, RUSL projects draw on aspects theorists such as Jane Jacob, Lewis Mumford and Leon Krier, and specific ideas of New Urbanism that promote the design of context responsive, walkable, diverse neighbourhoods linked to good systems of transit.

Principles of Landscape Urbanism offer specific ways to conceive of cities through the design of the environment, particularly the landscape, rather than just through the design of buildings. Inherent to this approach is the acceptance that a city is not a fixed, static entity; it is a series of interacting processes. As James Corner describes, '( $t$ )he projection of new possibilities for future urbanism must derive less from an understanding of form and more from an understanding of process - how things work in space and time.' $(2006,29)$ Corner describes the city as an ecology, suggesting that 'the promise of landscape urbanism is the development of a space-time ecology that 
treats all forces and agents working in the urban field and considers them as continuous networks of inter-relationships.' $(2006,30)$.

RUSL projects refer to a range of other theoretical frameworks in order to question, engage with context and structure responses. Kevin Lynch's ideas of urban legibility which advocates the analysis of urban realms in terms of paths, edges, districts, nodes and landmarks are foundational. (1960) These ideas are extended by reference to Quentin Steven's work, which considers tactics that support new or creative uses or behaviours in cities. Stevens' text, The Ludic City (2007), promotes different concepts of the within city, and his work with Karen Franck, Tying Down Loose Space (2007), advocates for the design of loose space that encourages a wide range of appropriation by its users. Ignasi de Sola-Morales Rubio's concept of terrain vague provides a further point of reference, particularly where a context has less precise, tangible or particular characteristics, but also an underlying sense of potential. (1995, 119-120)

Jeffrey's Hou's theory of Now Urbanism also offers useful ideas that aim to bring a sense of immediacy to urban design, advocating for the utilisation of resources and skills that are already available within a particular context. Small and/or temporary, but potent, transformations within a city allow testing residents and the city makers to understand how reprogramming a space or context may work in the long term. (2014) This approach is complementary to Gehl's principle of life-space-buildings, offering ways of supporting longer term, larger scale urban planning projects. RUSL's analytical and speculative research uses these ideas in various ways to analyse and visualise new ways of thinking about existing city contexts.

RUSL is part of an emergent Urban Environment Community of Practice within the University of Tasmania, which involves collaboration between the disciplines of architecture, planning, sociology, health and economics to explore an integrated understanding how social and cultural factors affect the urban realm. Strategic partnerships promote cross/inter/multi/trans disciplinary pedagogies and establish pathways to other research. The development of shared research practices and complementarity research fields allows for the identification of diverse research methods, providing a framework for ongoing engagement across and between disciplines. Theoretical exploration from diverse fields provides ways of understanding the problems at hand, with the physical and social context, both past and present providing a starting point for understanding the parameters of the research.

\section{RUSL Research Methods}

RUSL research aims to be productive, both through the collation of data that provides an understanding of historic and current conditions, and through the presentation of speculative propositions that suggest potential future scenarios. Projects employ a reflexive processes that engage in the interplay between different methods that draw on Frayling's tripartite definition of design research. A range of emergent methodologies frame processes for examining spatial, temporal and social urban issues, tailoring. Frayling's definitions to describe processes that are interconnected and iterative rather than singular and linear. 
- Research into design investigates the particularities of context, focusing on issues that are 'internal' to the site or project. Site analysis, site mapping and historical research are examples of research into design.

- Research for design involves explorations with a design application in mind, focusing on external conditions that are not directly related to the site/design, but offer relevant insights. Theoretical inquiry, precedent research, material investigations, scale comparisons or comparative mapping are examples of research for design.

- Research through design uses the process of design itself to explore research questions, focusing on the 'doing' or the 'making' of design and the subsequent insights revealed through these actions. Speculative proposals and prototypes are examples of research through design.

These methods investigate differing critical spatial practices, drawing together socioeconomic and demographic research to examine social, temporal and spatial urban issues. The nature of the problems means that clear questions are not necessarily known from the outset, but are developed throughout the process. Research does not involve a set of fixed experiments that are repeated; it is open ended, posing questions through projective thinking and speculation, illustrating Downton's belief that:

Design is not normally intended to produce a fully pre-conceived outcome, rather it is expected to produce change in the existing situation and hopefully offer fresh surprise and delight. $(2003,5)$

RUSL projects applying the reflections obtained from any findings from research for and into design to produce speculative ideas generated through processes of research through design. Speculation includes the development of broader values-based ideas that are tested through design propositions, with visualisations demonstrating transformations of places and spaces. The various research methods employed in RUSL projects can be understood through terminology developed by the Monash School of Art, Design and Architecture (MADA), which describes processes that are both speculative and indeterminate, but also productive. Research processes encompass a shift from architectural design traditions that focus on the production of 'things', to design research that involves on the exploration of 'issues'. This highlights that design research is not just about problem solving, but it also involves the examination of project possibilities; it is both speculative and projective. (MADA 2013) Particular emergent methods of design research can be identified, using tactics of: study, sample, illustrate, image, narrative or manifesto. These processes involve both documentation of existing conditions and projective or speculative processes that present new ideas. 


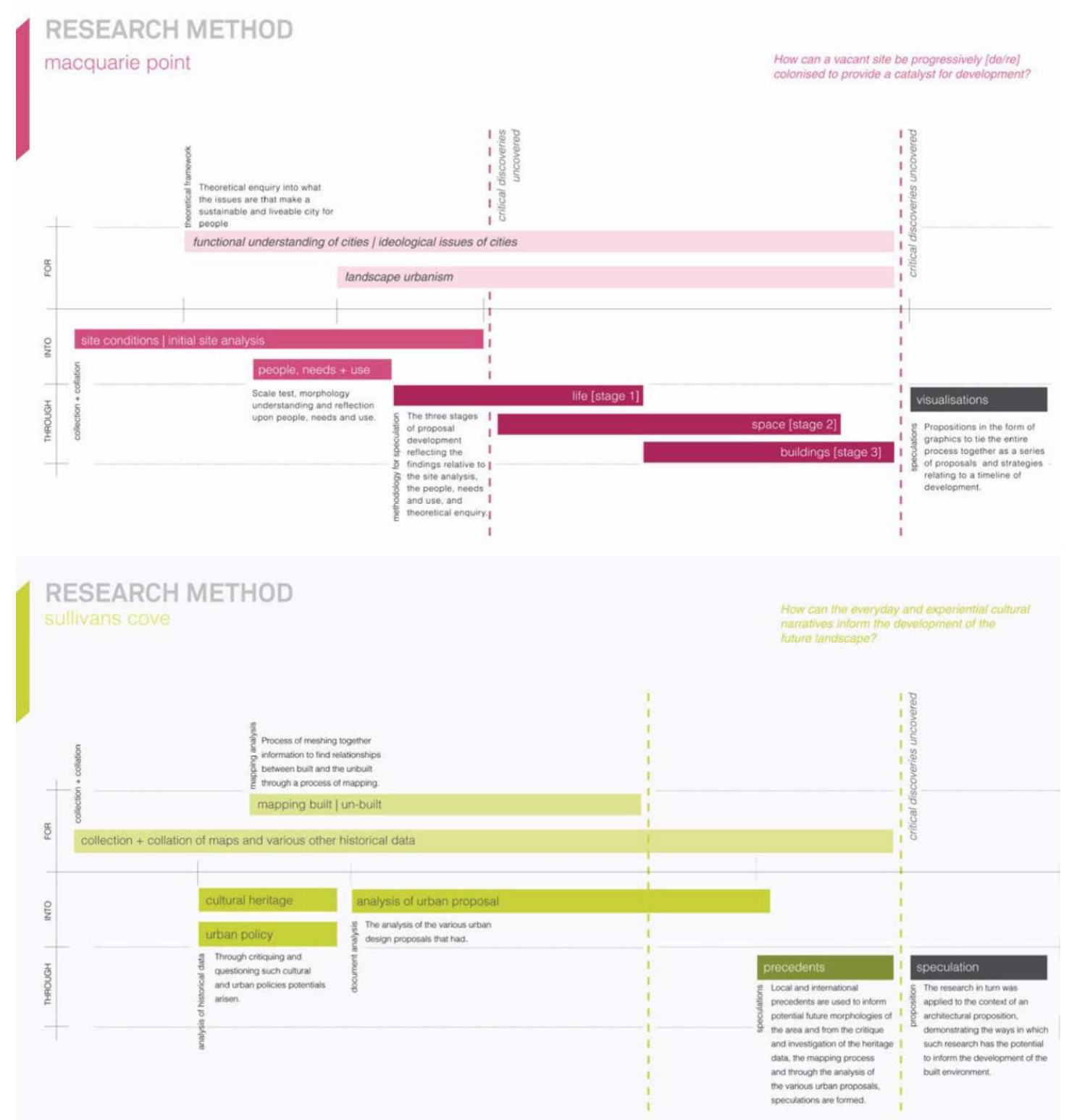

Figure 3: Visual mapping of research processes. Image: RUSL, 2010.

Studies involve the 'detailed examination and analysis of a subject, phenomenon.' (MADA 2013) This includes analysis of patterns of use and occupation and the cataloguing of spatial conditions. This may include mapping, documenting and analysing the built and natural landscape to record current conditions and reveal opportunities, through processes that can be understood as research into design. Mapping uncovers connections and relationships between places, highlighting patterns of use and connectivity, abstracting information to gauge particular conditions in isolation and making a reading of a place. Comparative mapping between different locations allows for site testing, revealing the potential complementarity of other uses for sites. Studies may also include aspects of the broader cultural landscape; social and cultural activities, values and events that provide an understanding of context in the broadest sense. 


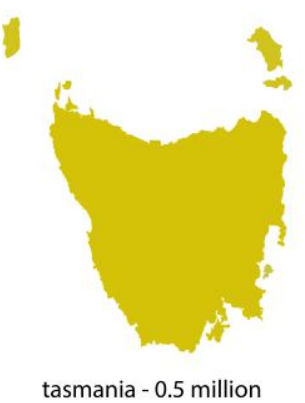

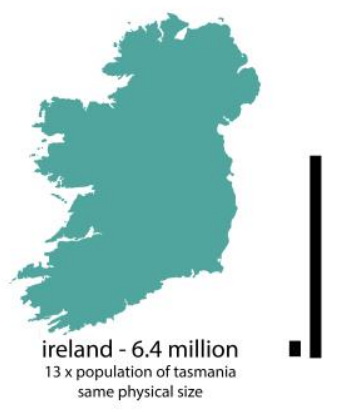

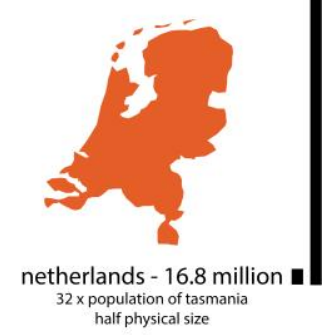

Figure 4: Comparative mapping of Tasmania, landmass versus population Image: Helen Norrie, 2012.

Studies from other disciplines may also inform design problems, particularly from fields of health, sociology, economics and planning. Analysis of conceptual or theoretical ideas, as well as exemplars or case-study precedents, allows for interpretation and the drawing together of strategies and tactics that can be reapplied in different conditions. This can be understood as research for design. Critical evaluation of this analysis creates a process of reflection-in-action, which may reveal further questions, mapping or other forms of investigation such as statistical analysis.

Projective and speculative processes that involve sampling, illustrating, and imaging, provide ways of visually testing projective or speculative ideas, each with a different format. Sampling involves processes similar to those used in music, in which small parts of a project are coopted into a new context. (MADA 2013) This may include grafting of precedents on to sites as a way to test or speculate on particular spatial ideas. This extends processes of research for design by reapplying ideas into a different context in order to reveal new readings. Similarly, illustrating ideas through the 'use of examples or comparisons' provides another form of speculation. (MADA 2013) This differs from sampling in that it involves visualising a particular idea, through three-dimensional diagrams and drawings to demonstrate a unique response to a design problem, which does not involve sampling. Images, or 'physical likeness or representation', provide ways of translating diagrammatic or strategic ideas into visualisations, which can demonstrate possible particular spatial and social opportunities. In particular this includes renders, montages or other photo realistic representations. (MADA 2013) Each of these different methods of visualization of speculative propositions can be understood as research through design.

Broader conceptual ideas may also be presented through a manifesto or the generation of narratives. A manifesto , or 'declaration of the intentions, motives, or views' provides a broader vision of ideas for exploration, which steps outside of the practical constraints', and is both speculative and projective. A narrative presents 'a story or account of events, experience, or the like, whether true or fictitious.' (MADA 2013) This allows for the development of scenarios, which draw on character profiles of the community to imagine new futures. Although each of these methods do not necessarily involve the visualisation of a specific spatial proposition, the projective and speculative processes constitute a form of research through design. In particular, the development of broader urban narratives can provide the framework for more 
detailed ideas. For example, ideas of the city as an 'urban playground', a 'social hub', or a 'campus', have provided unifying ideas that have shaped particular RUSL research projects.

RUSL projects involve 'creative leaps and lateral thinking', which Fraser suggests is one of the strengths of design research. They embrace 'a kind of improvisation, inventing and testing' of newly devised strategies, which challenge or subvert traditional processes. (Fraser 2013, 2) Hybrid research processes allow for the investigation of urban issues to evolve, rather than be constrained by the defined terms of reference or desired outcomes that often characterise consultancies. The unknown is embraced as part of the process; trying out an idea to see what comes of it, reflecting on this and then establishing ways to represent what it is that has been discovered. Differences in research processes between particular projects are mapped, identifying 'critical discoveries', which results in a shift in research process between into/for/through design. This mapping illustrates differences between research processes, providing a form of 'reflection-in-action' or research about design, and allowing hybrid research processes to be examined and compared. (Figure 2 )

\section{RUSL Research dissemination}

The format of the research outputs varies between projects, and findings are disseminated in different ways. Research is presented graphically in a series of reports under the SPECULATE banner, allowing outputs from different projects to be collated as a cohesive group. These reports are highly visual, and allow for the presentation of ideas to councils so that findings and speculative ideas can be discussed in group meetings. Projects are also represented in academic journals and professional conferences, allowing ideas to be disseminated to broader audiences, and to be described in more detail, particular in theoretical terms. The dual mode of presentation of the work, through SPECULATE reports or academic journals and/or professional conferences allows research to be communicated to specific audiences. Knowledge gained about projects in site-specific locations is presented in a way that allows these findings to be understood in a more generalised manner. Papers include critical reflection of research questions, methods, contexts and speculative ideas. This highlights the hybrid processes of research into/for/through design, with the representation of work allowing for research about design to provide a feedback loop that critical reflects on research outcomes (which may be questions) and the research processes themselves.

\section{Discussion}

Central to RUSL projects are a number of collaborative models that underpin different modes of practice-led research. Firstly, direct engagement between the university and local councils defines projects, shapes research questions and presents new knowledge or ways of understanding particular urban issues within regional municipalities. Secondly, projects are extended through research consultancies or via internships with the councils, which are supervised jointly by council and academic staff. This involves a different form of collaboration with outputs generally focused on more practical outcomes. Thirdly, research methods embed an engagement with the teaching research nexus, providing new insights into both teaching and research practices, and into the field of enquiry itself. 
Working collaboratively with councils provides interesting opportunities to establish new ways of understanding problems, questioning traditional ideas and process. The relationship of RUSL to the local councils is not one of a consultant employed to undertake a defined scope of work, but as a partner in a process of collaborative research in which the field of exploration evolves throughout the projects. Collaboration between the council and the university spans the divide characterized by Schön as the high ground in which 'manageable problems lend themselves to application of research-based theory and technique' and the swamp where 'messy confusing problems defy technical solution'. (1978, 3) It allows everyday and 'messy' problems to be informed through theoretical research, which expands the conceptual understanding and/or provides a broader understanding or context that enlightens these issues. This collaborative research allows an engagement in pragmatic issues in alternative ways, subverting traditional approaches and reinforcing connections between theory and practice. The process of speculation produces ideas that can either be seen as provocations or realistic propositions for future development that may be more immediately viable. It is simultaneously productive, yet indeterminate.

This process of collaboration engages the council in a process of reflection-in-action, allowing them to consider ideas that might not be possible within the standard, outcome-lead council business. However, there is a need to balance between the practical concerns of the council and their expectation of pragmatic and 'directly achievable' outcomes, and the possibilities that more theoretical or speculative research offers. Within each project there is a continual negotiation about the role of theoretical ideas in both the process and the final outputs. Although the council are interested in the outcomes of theoretical enquiry, they are sometimes not necessarily convinced by the need to foreground the presentation of outputs with these concepts.

The process with council demands that the theoretical approach generated through the academic research frame be translated into practical, direct, and 'real' outcomes. The intention is for the university to act as a provocateur sitting outside of the outcome focused structure of the council. This presents a challenge to engage with theoretical ideas and to frame the projects in terms of the broader generic ideas, rather than merely site-specific conditions. There is often pressure from councils to steer towards projects most directly understood as 'useful' outcomes, rather than broader level conceptual or theoretical thinking. RUSL projects offer speculative propositions that can help to expand the conception of briefs, rather than presenting design solutions that should be developed as professional consultancies.

Projects involve a reciprocal uncovering and sharing of information. Using visual processes to communicate with the council offers a more interactive or imaginative method than traditional written research reports. Visualisations - sampling, illustrations, images - of both analysis and speculative provocations are a powerful way to capture the imagination and contribute to a broader audience. It provides a way of examining spatial, temporal and social issues and ideas through testing possible scenarios. This allows for questions about urban futures to be presented to the public as both provocations and possible future solutions, extending the process of critical reflection and reinforcing the open-ended nature of this design research. 


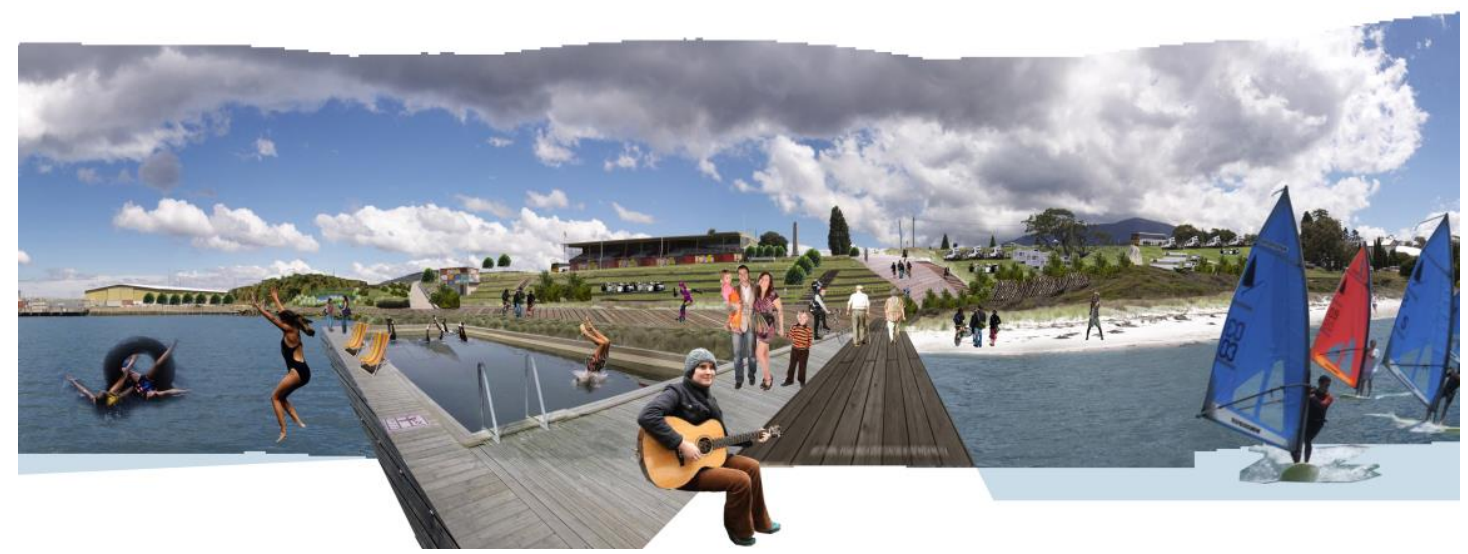

Figure 5: Visualisation of speculative idea for Macquarie Point. Image: Rebekah Verrier and Hannah Gora, 2010.

RUSL projects provide a model of design research that engages with real-world issues, which presents a form of practicum where students learn by doing, working with academic staff who act as a 'coach' - demonstrating, advising, questioning and criticising. (Schön 1987, 37-38). Research-based teaching immerses the student fully as a collaborator in the research task. The 'coach' or academic supervisor works with the students towards a common goal an 'equal' researcher, rather than instructing from 'above'. The research shapes the learning task and there is a perceived 'two-way' relationship between academic and student. (Griffiths 2004, 772) Working in small research teams means that students learn from their peers through a process of reflection-in-action, and this reinforces and extends the critical spatial practices that are central to the research projects. The engagement between the student and the coach/supervisor provides another feedback loop, reinforcing the iterative processes that ground the projects. The process of reflection-in-action, reflection upon the reflection-in-action, and a reflection on the resulting outputs is the kind of cascading, yet circular, process that occurs throughout RUSL project.

Several challenges are also inherent to this process. Firstly, the open-ended nature of design research requires that students are not working on clearly defined tasks, they are required to participate in framing research questions and developing appropriate methods. For some students this is a challenging, if not impossible task, which frequently requires the intervention of the supervisor to structure the research task. Secondly, the requirement for academic staff to shift between the roles of immersive collaborator and objective assessor can be problematic, and the need to create this distinction can potentially destabilise the collaborative relationship. Thirdly, the openended nature of the research also means that it is difficult to communicate in advance the scope of work required within the framework of assessment tasks. This contrasts with the increasing expectation to provide clear frameworks for assessment. There is a risk of closing down opportunities if the research leads to unexpected but productive directions that are not reflected in the 'contract' of the assignment outline and assessment rubric. Key to the negotiation of this territory is placing the emphasis on assessing the process rather than product. (Owen and Norrie 2013) 


\section{Conclusion}

The collaborative practice-led design research between RUSL and local councils reconsiders the architect's role in the development of cities, not just through the design of individual buildings, but as part of creative teams speculating urban futures. RUSL takes up the role of the 'theorist' to work in collaboration with the councils as 'policy-makers and 'city builders'. Projects examine urban issues, expanding the disciplinary boundaries of architecture to include, planning, geography, sociology, health, politics and economics. The dual mode of dissemination of illustrated reports that present visualise analysis and speculative propositions, along with more traditional outputs of academic papers, examines ways that practice-led research can overcome the primacy of the written word. Providing more diverse forms of outputs allows for the communication of ideas to broader audiences, and this allows the research to be more accessible. Balancing between the exploration of theoretical ideas and the presentation of practical outcomes seeks to form new relationships between theory and practice.

Malcolm Gladwell (2000) suggests that change involves the coordinated engagement of three types of people, who work collaboratively to make ideas contagious:

- connectors who know large numbers of people and make connections between groups

- mavens, or information specialists, who accumulate knowledge and connect people to it

- "salesmen", the "persuaders" with negotiating skills.

Drawing on Gladwell's thinking, RUSL aims to operate as both connector and maven through conversations across different council departments, between councils as well as with the state government. RUSL projects collate and communicate common concerns for site-specific urban issues and broader 'whole city' or regional thinking, and the challenge for RUSL is to explore how these projects, ideas and actions can become contagious. Clearly defining RUSL's role in this process, and creating more opportunities for expanding this work, is central to increasing the agency of this work to actively address future urban challenges.

\section{References}

Brew, A. (2011) 'The Nature of Research: Inquiry' in Academic Contexts, London: Routledge, pp. 145-154.

Corner, J. (2006) 'Terra Fluxus'. In Waldheim, C. (ed.) Landscape Urbanism Reader. New York: Princeton Architectural Press pp. 21-33.

de Sola-Morales Rubio, I. (1995) 'Terrain Vague', Anyplace, Cambridge MA: MIT Press, pp.188-123.

Downton, P. (2003) Design Research. Melbourne: RMIT University Press.

Australian Government, Australian Research Council (2012) 'Excellence in Research for Australia 2012', Canberra: Commonwealth of Australia.

OECD (2002), 'Frascati Manual: Proposed Standard Practice for Surveys on Research and Experimental Development', Paris. 
Franck, K. and Stevens, Q. (2007) Loose space : possibility and diversity in urban life. London: Routledge.

Fraser, M. (2013) Design Research in Architecture: an overview. Farnham, England; Burlington, USA: Ashgate.

Frayling, C. (1993) 'Research in Art and Design' Royal College of Art Research Papers series 1(1) 1(1).

Gladwell, M. (2000). The tipping point: How little things can make a big difference. Boston: Little, Brown.

Griffiths, R. (2004) 'Knowledge production and the research-teaching nexus: the case of the built environment disciplines,' Studies in Higher Education, 29, 6, pp. 717.

Hou, J. (2014) 'NOW Urbanism; The Future City is here.' presented at urb4nize! Citopia Now, Internationales Festival fur urbane Erkundungen, Vienna. Available at https://vimeo.com/99124337. Accessed March, 2015. Lynch, Kevin (1960). The Image of the City, Cambridge MA: The MIT Press.

Marelja, M. and Norrie, H. (2013). 'Teenagers and the City', Paper presented at the 6th Annual International Urban Design Conference, Sydney.

Murray, S. (2013). 'Design Research: Translating Theory into Practice', in M. Fraser (Ed.), Design Research in Architecture: an overview, Farnham, England; Burlington, USA: Ashgate pp. 95-116.

Norrie, H. (2013) Urban Narratives: Museums and the City. (Doctor of Philosophy), Melbourne: University of Melbourne.

Norrie, H. (2014) 'Regional Urban Studies Laboratory (RUSL): engaging universities in collaborative design research with government policy-makers', paper presented at the Architectural Design Research Symposium, Wellington, Victoria University.

Norrie, H. and Bennett, A. (2009) 'Sustainable Cities: Planning, Development and Design', paper presented at the 5th International Conference of the Association of Architecture Schools of Australasia 2009, Sustainable Theory/Theorizing Sustainability, Wellington, Victoria University.

Norrie, H., Englund, R., Stoklosa, T., and Wells, D. (2014) 'Survival and Revival of Rural and Regional Towns', paper presented at the Australian Regional Development Conference, Albury.

O'Byrne, K. and Norrie, H. (2013) 'The City as an Urban Playground', paper presented at the 6th Annual International Urban Design Conference, Sydney.

Owen, C. and Norrie, H. (2013). 'Advanced Design Research: exploring the teaching research nexus', paper presented at the 7th Annual Conference of the Association of Architecture Schools of Australia, Melbourne.

Schön, D. A.(1987) Educating the Reflective Practitioner, San Francisco: Jossey-Bass.

Rendell, J. (2004) 'Architectural research and disciplinarity', in Architectural Research Quarterly, 8/02, pp. 141-147. 
Rendell, J. (2013). 'A Way with Words: Feminists Writing Architectural design Research', in M. Fraser (Ed.), Design Research in Architecture: an overview, Farnham, England; Burlington, USA: Ashgate 117-136.

Steven, Q. (2007) The Ludic City: Exploring the Potential of Public Spaces, London: Routledge.

Dr Helen Norrie is an academic in the School of Architecture \& Design at the University of Tasmania, and founder of the Regional Urban Studies Laboratory (RUSL), a collaborative urban design research project that explores the opportunities for the future sustainable urban development, particularly in regional centres. RUSL works directly with local authorities to examine urban issues in small towns and cities, developing collaborative research that examines the spatial, temporal and social aspect of urban settlements. RUSL develops research through the medium of design, providing a crossover between the disciplines of architecture, planning, sociology and economics provide fertile ground for research investigations. The ideas underpinning RUSL research were developed through Helen's PhD research Urban Narratives: Museums and the City (2013) which examines the agency of architecture to engage with broader urban narratives.

Email: $\underline{\text { Helen.Norrie@utas.edu.au }}$

Judith Abell is a lead researcher for the Regional Urban Studies Laboratory (RUSL) at the University of Tasmania. She is a multidisciplinary design consultant and writer with a background in architecture, fine arts and design related research. Trained in architecture and sculpture at the University of Tasmania, Judith has always operated within the 'places' where design intersects with other aspects of life. Throughout her 15-year architectural career in Hobart and London, she has been involved in projects relating to conservation, office space planning, school design, spaces for special education and interior design. 